\title{
Supporting the Education of Nurse Practitioners and Physician Assistants in Meeting Shortages in Mental Health Care
}

\author{
Mary K. Morreale ${ }^{1}$ (D) $\cdot$ Richard Balon $^{1} \cdot$ John Coverdale $^{2} \cdot$ Alan K. Louie $^{3} \cdot$ Eugene Beresin $^{4} \cdot$ Anthony P. S. Guerrero $^{5}$. \\ Rashi Aggarwal $^{6} \cdot$ Adam M. Brenner $^{7}$
}

Received: 27 May 2020 / Accepted: 31 May 2020 /Published online: 11 June 2020

(C) Academic Psychiatry 2020

A significant shortage of psychiatrists is projected to occur by 2024 without substantial intervention, on the basis of estimates of population growth and the number of physicians both entering and exiting practice [1]. In fact, some rural areas are already deficient in psychiatrists and mental health resources [2]. Psychiatry has responded to this challenge by both expanding existing residency programs and creating new residency programs. Consequently, an approximate $20 \%$ increase has occurred in the number of resident positions in psychiatry between 2014 and 2019 [3]. Despite this expansion, however, it is likely that physician assistants (PAs) and nurse practitioners (NPs) will deliver an increasing amount of care to patients with mental illness in order to fill practice gaps.

Specialization in behavioral health is possible through several avenues for both NPs and PAs. Regarding NPs, both master- and doctoral-level psychiatric NP programs exist, some of which offer didactic learning online and leave students to secure clinical preceptors on their own [4]. Eligibility requirements for a 5-year psychiatric NP certification include at least $500 \mathrm{~h}$ of supervised clinical work in an accredited program with training in at least two therapeutic modalities; completion of three graduate-level courses in physiology/

Mary K. Morreale

mmorreale@med.wayne.edu

1 Wayne State University, Detroit, MI, USA

2 Baylor College of Medicine, Houston, TX, USA

3 Stanford University, Stanford, CA, USA

4 Harvard Medical School, Boston, MA, USA

5 University of Hawai'i John A. Burns School of Medicine, Honolulu, HI, USA

6 Rutgers New Jersey Medical School, Newark, NJ, USA

7 University of Texas Southwestern Medical Center, Dallas, TX, USA pathophysiology, health assessment, and pharmacology; and successful completion of an examination given by the American Nurses Credentialing Center [5]. For both NPs and PAs, 1-year programs exist (some of which are integrated into academic departments of psychiatry) that include both didactic and clinical exposure [6,7]. Either independent of or following a postgraduate program, PAs are able to sit for a certificate of added qualification, which is a voluntary credential that can be earned in various specialties, including psychiatry [8]. Unfortunately, the number of licensed NPs and PAs who choose to pursue certification in psychiatry is currently less than $2 \%[9,10]$.

For the majority of PAs who do not choose to pursue postgraduate specialization, accreditation standards for curricula related to behavioral health and clinical psychiatry in graduate PA programs are ambiguous and "may cause some PA students to receive limited or inconsistent exposure to the field of psychiatry" [11]. For example, the Accreditation Review Commission on Education for the Physician Assistant Accreditation Standards does not specify time requirements for either didactic curricula or clinical experience in psychiatry [12]. In addition, these standards contain no specification for who should be supervising PA students clinically, stating only that "supervised clinical practice experience preceptors have valid certification that allows them to practice in the area of instruction." As Rakofsky and Ferguson [11] note, there is no specific "guidance with regard to important items such as the following: the breadth of exposure to the different psychiatric conditions, duration of the supervised clinical experience, nor learning objectives during that experience" (p. 687).

From a legislative standpoint, varying levels of supervision are required for NPs and PAs. Twenty-one states allow NPs to practice without physician collaboration or supervision [13]. Although most jurisdictions in the USA require some level of supervision of PAs, which is either undefined, depending on the state, or ranging from physician "ready availability" for communication to intermittent physical presence, two states 
allow PAs to practice without supervision, and two require collaboration (either communication available for consultation or monthly meetings via email, phone, or direct physical contact) [14]. These requirements are vulnerable to change as evidenced by the elimination of supervision in some states during the COVID-19 pandemic and a recent executive order endorsing practice without physician oversight $[15,16]$. Regarding the authority to prescribe controlled substances, the vast majority of states allow both NPs and PAs to write prescriptions for medications within schedules II-V [17].

As academic psychiatrists, we have a responsibility for ensuring that our patients receive the best care possible, and this responsibility makes us stakeholders in whatever systems of training are devised for NPs and PAs. Given the depth of our training (e.g., psychiatric residents likely have $500 \mathrm{~h}$ of supervised clinical activity within the first 3 months of intern year), it makes sense from an educational standpoint that we take the lead in developing close, collaborative relationships with both NP and PA programs in order to strengthen their educational efforts and clinical experiences. Three publications within this Academic Psychiatry describe such efforts on the part of academic departments of psychiatry. For example, at Emory University School of Medicine [11], PA students are "fully" integrated into the medical student psychiatry clerkship, with psychiatrists serving as preceptors. The Department of Psychiatry at the University of Colorado School of Medicine [6] hosts a 1-year postgraduate "fellowship" for PAs, which offers training in outpatient, inpatient, consult-liaison, and correctional psychiatry in collaboration with departmental psychiatry residents and fellows. Finally, within the Public and Community Psychiatry Fellowship at Case Western Reserve School of Medicine [7], advanced practice nurses and psychiatry fellows train alongside each other in a collaborative educational experience.

These cooperative programs will likely have benefit beyond concrete aspects of education. First, they could ensure that a desired level of competency is achieved for the clinical responsibilities of NPs and PAs, which is especially important in light of psychiatry's workforce shortages. In addition, they might attract more NPs and PAs into the field of psychiatry and enhance academic collaboration. Finally, with careful consideration and monitoring, such programs could potentially enhance the training of psychiatric residents. As the Accreditation Council for Graduate Medical Education [18] recognizes in the current description of psychiatry residency training requirements, "The clinical learning environment has become increasingly complex and often includes care providers, students, and post-graduate residents and fellows from multiple disciplines. The presence of these practitioners and their learners enriches the learning environment" (p. 7).

In order for our profession to continue to distinguish itself, we too must ensure that we are educating psychiatrists to practice at the full potential of our specialty. Psychiatry residents and fellows should be trained to implement evidence-based psychopharmacological and psychotherapeutic treatments and even to consider expanding psychotherapeutic competencies $[19,20]$. In addition, we should try to reverse the declining numbers of filled fellowship positions [21]; promote opportunities for training in neuromodulation and for prescribing buprenorphine, ketamine, and esketamine; and provide enhanced elective experiences in addiction psychiatry, geriatric psychiatry, and psychosomatic medicine. We must develop and maintain our expertise in the management of complex psychiatric cases.

Here is a wonderful opportunity for leadership across psychiatry, nursing, and the allied professions. There are no easy fixes, and because solutions will take time to bear fruit, there is no time to waste. Let us engage in developing a plan for working together to better meet the mental health needs of our population.

Disclosures On behalf of all authors, the corresponding author states that there is no conflict of interest.

\section{References}

1. Satiani A, Niedermier J, Satiani B, Svendsen DP. Projected workforce of psychiatrists in the United States: a population analysis. Psychiatr Serv. 2018;69(6):710-3.

2. Guerrero APS, Balon R, Beresin EV, Louie AK, Coverdale JH, Brenner A, et al. Rural mental health training: an emerging imperative to address health disparities. Acad Psychiatry. 2019;43:1-5.

3. Accreditation Council for Graduate Medical Education. GME Data Resource Book 2018-2019. Available at https://www.acgme.org/ About-Us/Publications-and-Resources/Graduate-MedicalEducation-Data-Resource-Book. Accessed 4/28/20.

4. Nurse.org. 10 top psychiatric nurse practitioner programs 2020. Available at https://nurse.org/articles/top-psychiatric-nursepractitioner-programs/. Accessed 4/10/2020.

5. American Nurses Credentialing Center. Psychiatric-mental health nurse practitioner (across the lifespan) certification. Available at https://www.nursingworld.org/our-certifications/psychiatricmental-health-nurse-practitioner/. Accessed 3/6/20.

6. Novoa K, Gaffaney M, Rylander ML. Addressing an unmet need: the development of a postgraduate physician assistant training program in psychiatry. Acad Psychiatry. 2020. https://doi.org/10.1007/ s40596-020-01220-1.

7. Runnels P, Ruggiero R. Collaborative training in fellowship: implications for psychiatric workforce development. Acad Psychiatry. 2015;39:695-8

8. National Commission on Certification of Physician Assistants. Specialty certificates of added qualifications. Available at https:// www.nccpa.net/specialty-caqs. Accessed 4/10/2020.

9. American Association of Nurse Practitioners. NP fact sheet. Available at https://www.aanp.org/about/all-about-nps/np-factsheet. Accessed 4/23/2020.

10. National Commission on Certification of Physician Assistants. 2018 statistical profile of certified physician assistants. Available at https://prodcmsstoragesa.blob.core.windows.net/uploads/files/ 2018StatisticalProfileofCertifiedPhysicianAssistants.pdf. Accessed 4/23/2020. 
11. Rakofsky JJ, Ferguson BA. Assisting undergraduate physician assistant training programs: the role of academic psychiatry departments. Acad Psychiatry. 2015;39:687-90.

12. Accreditation Review Commission on Education for the Physician Assistant, Inc. Accreditation manual. Available at http://www.arcpa.org/wp-content/uploads/2020/01/AccredManual-5th-edition-11. 19.pdf. Accessed 4/10/2020.

13. American Association of Nurse Practitioners. Practice information by state. Available at https://www.aanp.org/practice/practiceinformation-by-state. Accessed 3/3/2020.

14. American Medical Association. Physician assistant scope of practice. Available at https://www.ama-assn.org/sites/ama-assn.org/ files/corp/media-browser/public/arc-public/state-law-physicianassistant-scope-practice.pdf. Accessed 3/5/20.

15. The Office of Governor Gretchen Whitmer. Executive order 2020 30 (COVID-19). Available at https://www.michigan.gov/whitmer/ 0,9309,7-387-90499_90705-523481\%2D\%2D,00.html. Accessed $4 / 6 / 2020$.

16. White House. Executive order on protecting and improving medicare for our nation's seniors. Available at https://www.whitehouse. gov/presidential-actions/executive-order-protecting-improvingmedicare-nations-seniors $/$ fbclid=IwAR2ndL16C7JoR3 3IfDLWNpxaxxGy9OWItrqQpJv5vYibSzkJyw9fdH_dnO0. Accessed 3/5/20.
17. American Academy of Physician Assistants. PA prescribing. Available at https://www.aapa.org/wp-content/uploads/2017/03/f833-4-8256527 dk6DMjRR Prescribing IB 2017 FINAL.pdf. Accessed 4/23/2020.

18. Accreditation Council for Graduate Medical Education. ACGME program requirements for graduate medical education in psychiatry. Effective July 1, 2019. Available at https://www.acgme.org/Portals/ 0/PFAssets/ProgramRequirements/400 Psychiatry_2019.pdf?ver= 2019-08-26-134127-827. Accessed 4/26/2020.

19. Accreditation Council for Graduate Medical Education. Psychiatry milestones. Available at https://www.acgme.org/Portals/0/PDFs/ Milestones/PsychiatryMilestones2.0.pdf?ver=2020-03-10-152105537. Accessed 5/27/20.

20. Cabaniss DL, Holoshitz Y. Different patients, different therapies: optimizing treatment using differential psychotherapeutics. New York: WW Norton \& Company; 2019.

21. Balon R. Subspecialty training: time for a change. Acad Psychiatry. 2017;41(4):558-60.

Publisher's Note Springer Nature remains neutral with regard to jurisdictional claims in published maps and institutional affiliations. 